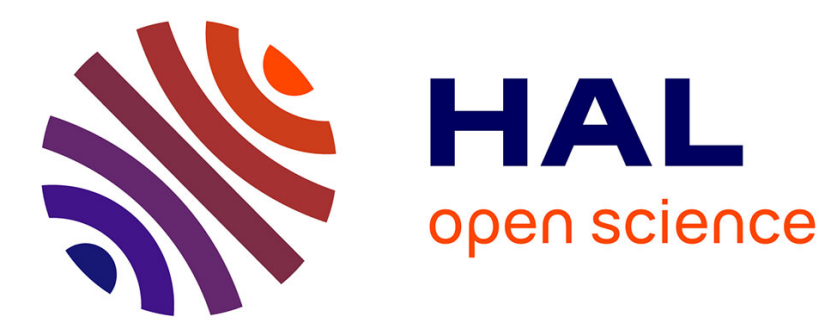

\title{
A high performance liquid chromatography tandem mass spectrometry for the quantification of tacrolimus in human bile in liver transplant recipients
}

C. Tron, M. Rayar, A. Petitcollin, J.-M. Beaurepaire, C. Cusumano, M.-C. Verdier, P. Houssel-Debry, C. Camus, K. Boudjema, E. Bellissant, et al.

\section{To cite this version:}

C. Tron, M. Rayar, A. Petitcollin, J.-M. Beaurepaire, C. Cusumano, et al.. A high performance liquid chromatography tandem mass spectrometry for the quantification of tacrolimus in human bile in liver transplant recipients. Journal of Chromatography A, 2016, 1475, pp.55-63. 10.1016/j.chroma.2016.10.075 . hal-01414963

HAL Id: hal-01414963

https://hal-univ-rennes1.archives-ouvertes.fr/hal-01414963

Submitted on 19 Jan 2017

HAL is a multi-disciplinary open access archive for the deposit and dissemination of scientific research documents, whether they are published or not. The documents may come from teaching and research institutions in France or abroad, or from public or private research centers.
L'archive ouverte pluridisciplinaire HAL, est destinée au dépôt et à la diffusion de documents scientifiques de niveau recherche, publiés ou non, émanant des établissements d'enseignement et de recherche français ou étrangers, des laboratoires publics ou privés. 


\section{A high performance liquid chromatography tandem mass spectrometry for the quantification of tacrolimus in human bile in liver transplant recipients}

Camille Tron $^{\mathrm{a}, \mathrm{b}, \mathrm{c}}$, Michel Rayar ${ }^{\mathrm{c}, \mathrm{d}}$, Antoine Petitcollin ${ }^{\mathrm{a}, \mathrm{b}, \mathrm{c}}$, Jean-Marie Beaurepaire ${ }^{\mathrm{d}}$ Caterina Cusumano $^{\mathrm{d}}$, Marie-Clémence Verdier ${ }^{\mathrm{a}, \mathrm{b}, \mathrm{c}}$, Pauline Houssel-Debry ${ }^{\mathrm{c}, \mathrm{d}}$, Christophe Camus ${ }^{\mathrm{c}, \mathrm{e}}$, Karim Boudjema ${ }^{\mathrm{c}, \mathrm{d}}$, Eric Bellissant $^{\mathrm{a}, \mathrm{b}, \mathrm{c}}$ and Florian Lemaitre ${ }^{\mathrm{a}, \mathrm{b}, \mathrm{c}}$

a. Rennes University Hospital, Department of Clinical and Biological Pharmacology and Pharmacovigilance, Pharmacoepidemiology and Drug Information Center, Rennes, France.

b. Rennes 1 University, Faculty of Medicine, Laboratory of Experimental and Clinical Pharmacology, Rennes, France.

c. Inserm, CIC-P 1414 Clinical Investigation Center, Rennes, France.

d. Rennes University Hospital, Hepato-biliary and digestive surgery Unit, Rennes, France.

e. Rennes University Hospital, Medical Intensive Care Unit, Rennes, France

\section{Corresponding author}

Camille TRON, Pharmacology Department, Rennes University Hospital, 2, rue Henri Le Guilloux, 35033 Rennes cedex; Tel: 0033223234713; Fax: 0033299284184; Mail : camille.tron@chu-rennes.fr

\section{HIGHLIGHT :}

- $\quad$ An HPLC-MS/MS method was developed to quantify tacrolimus in bile

- Sample purification combined protein precipitation and liquid-liquid extraction

- The assay fulfilled acceptance criteria for bio-analytical method validation

- $\quad$ The method was successfully applied to the analysis of bile from liver transplants

- Drug monitoring in bile could be an alternative approach for treatment optimization

\footnotetext{
Abstract

Tacrolimus whole-blood concentrations imperfectly reflect concentrations at the effect site. Tacrolimus concentrations in the transplanted organ could be more relevant to predict rejection events. Because liver biopsy cannot be repeatedly performed after liver transplantation, we suggested measuring tacrolimus in the bile to have a cost-effective and clinically implementable surrogate marker of intrahepatic tacrolimus concentration. We developed and fully validated a liquid chromatography-tandem mass spectrometry method for the determination of tacrolimus in human bile. Sample purification was achieved using protein precipitation and liquid-liquid extraction with ethyl-acetate. Gradient elution was performed using a $\mathrm{C} 18$ analytical column with a 5 min run-time. The method was linear from 0.5
} 
$\mathrm{ng} / \mathrm{mL}$ to $20 \mathrm{ng} / \mathrm{mL}$. In this concentration range, within-day and between-day precisions as well as overall bias were within $\pm 15 \%$. Matrix effect was fully corrected by the internal standard (ascomycin). The assay was optimized to achieve good selectivity in this complex biological matrix. Tacrolimus was found to be stable in bile stored 6 months at $-80^{\circ} \mathrm{C}$, after 3 freeze and thaw cycles, 20 hours at room temperature and 24 hours in extracts kept at $15^{\circ} \mathrm{C}$ in the auto-sampler. The method was applied to quantify tacrolimus in bile from liver transplant recipients. It allowed getting preliminary data about tacrolimus excretion profile in bile and showed the lack of correlation between tacrolimus whole blood concentration and tacrolimus liver exposition. This alternative and innovative analytical approach of tacrolimus bio-analysis appears suitable for further studies evaluating relevance of biliary tacrolimus concentration as a new pharmacological marker of immunosuppressive activity.

Keywords: tacrolimus; high performance liquid chromatography; mass spectrometry; bile; alternative matrix; therapeutic drug monitoring

\section{Introduction}

Long-term survival following liver transplantation has slowly evolved during the last five years. The rate of acute graft rejection (ACR) also remained stable with a frequency of about $8-15 \%$ at one year despite effective immunosuppression [1]. Cornerstone of allograft rejection prevention, tacrolimus prevents the immune response against the graft by inhibiting interleukin-2 production by lymphocyte $\mathrm{T}$ cells [2]. The drug presents highly variable pharmacokinetics and narrow therapeutic range making challenging the achievement of the balance between therapeutic efficacy and occurrence of side effects [3]. Therapeutic drug monitoring (TDM) of tacrolimus levels in whole-blood contributed to decrease the risk of ACR as well as the onset of adverse reaction [4]. However, some patients exhibit ACR while having blood levels within the recommended therapeutic range. This suggests that tacrolimus trough whole-blood concentrations imperfectly reflect tacrolimus concentrations at the effect site. Thus, looking for novel approaches of immunosuppressive drugs monitoring is needed to better prevent ACR. In a prospective study in liver transplant recipients, Capron et al. [5] demonstrated the lack of correlation between tacrolimus trough whole-blood concentrations and the score of graft rejection, whereas tacrolimus intra-hepatic and peripheral blood mononuclear cells (PBMC) concentrations correlated well with incidence and intensity of histologically proved ACR. This work suggested that measuring tacrolimus concentrations in liver biopsy or in PBMC could better predict clinical outcomes. The relevance of the determination of immunosuppressive drug concentration in the transplanted organ was also highlighted by Staatz et al. [6]. However, such approaches of tacrolimus quantification are either invasive or expensive and the analytical workflow might be difficult to implement in daily clinical and laboratory practice [4]. We hypothesized that tacrolimus concentration in bile could be a surrogate marker of tacrolimus intra-hepatic concentration. The measurement of tacrolimus in bile appears cost-effective and suitable with clinical practice when T-tube biliary drainage is inserted in patients during surgery. Tacrolimus biliary concentration could reflect the free and non-metabolized fraction of the drug available at the target organ which is responsible for its pharmacological effect. 
Besides, tacrolimus is extensively metabolized by the liver and biliary excretion is thought to be the major route of elimination of its metabolites [7]. Polymorphisms in genes involved in this metabolism are a major cause of treatment response variability between patients [6]. Thus, tacrolimus concentration in bile could directly depend on the magnitude of drug metabolism, leading to provide valuable information about its pharmacokinetics. Studies reporting tacrolimus determination in bile are sparse and were published a few decades ago [8-10]. They are mainly focused on investigating the drug metabolic pathway without any extensive description of the analytical validation which is unfortunate because this matrix is known to be associated with several bioanalytical challenges [11]. Bile is an unconventional alternative matrix for TDM and demonstration of the reliability of the analysis is a critical step before any clinical application. Thus, prior to investigating whether biliary tacrolimus concentration could be a good marker of its immunosuppressive activity, we aimed at developing and validating, according to international guidelines [12], a high performance liquid chromatographytandem mass spectrometry (HPLC-MS/MS) method for the determination of tacrolimus in bile from liver transplant recipients. The analytical method was then applied to analyze bile samples from liver transplant recipients.

\section{Material and methods}

\subsection{Chemicals and material}

Tacrolimus was purchased from LGC standards (Folsheim, France). Ascomycin was purchased from Sigma-Aldrich (Saint-Quentin, France). Methanol and acetonitrile of LC/MS grade were purchased from Carlo Erba Reagents (Val de Reuil, France). Ethyl acetate, methyl-ter-butyl ether (MTBE) and dichloromethane were obtained from VWR international (Fontenay sous Bois, France). Ammonium acetate, zinc sulfate heptahydrate and formic acid were obtained from Fisher Chemicals (Waltham, USA). Water was purified using a Milli-Q® Ultrapure Water System (Merck Millipore, Milford, MA, USA). Beta-glucuronidase enzymes from E. Coli (type IX-A), Helix pomatia and bovine liver origins were purchased from Sigma-Aldrich (Saint-Quentin, France). OASIS ${ }^{\circ}$ HLB SPE 96-wells plate (30 mg) and OSTRO® 96-wells plates were purchased from Waters (Saint-Quentin, France).

Human bile was collected from the T-tube biliary drainage inserted in biliary anastomosis during the surgical procedure. Drug free human bile was collected before the onset of the immunosuppressive treatment. Drug-free bile samples from 7 individual liver transplant recipients were used to prepare a batch of pooled biles used in the validation and the clinical application analysis.

\subsection{HPLC-MS/MS equipment and conditions}

The chromatographic system (ThermoFisher, San Jose, CA, USA) included a Surveyor Autosampler and an HPLC Surveyor MS pump. A C18 Hypersil Gold column $(50 \times 2.1 \mathrm{~mm}, 3 \mu \mathrm{m})$ fitted with a guard column (10 x $2.1 \mathrm{~mm}, 3 \mu \mathrm{m})$ (Thermo Electron, Dreieich, Germany) was used and maintained at a constant temperature of $60^{\circ} \mathrm{C}$. The autosampler was set at $15^{\circ} \mathrm{C}$ during analysis. To measure tacrolimus in bile, gradient elution was performed with a mobile phase composed of a mixture of $0.1 \%$ formic acid and $2 \mathrm{mM}$ ammonium acetate in water (eluent $\mathrm{A}$ ) or in acetonitrile (eluent B). A multistep 
gradient adapted from Dubbelboer et al. [13] was used at a flow rate of $0.4 \mathrm{ml} / \mathrm{min}$ and was programmed as follows: equilibration at initial conditions with $40 \%$ of $\mathrm{B}$, increase to $70 \%$ of $\mathrm{B}$ from 0 min to $0.1 \mathrm{~min}$, increase to $75 \%$ of $\mathrm{B}$ from $0.1 \mathrm{~min}$ to $1.4 \mathrm{~min}$, increase to $100 \%$ of $\mathrm{B}$ from $1.8 \mathrm{~min}$ to $2.45 \mathrm{~min}$, stabilization at $100 \%$ of B from $2.45 \mathrm{~min}$ to $3.10 \mathrm{~min}$, reversion to the starting conditions at $40 \%$ of B from $3.1 \mathrm{~min}$ to $3.15 \mathrm{~min}$ and re-equilibration with the initial composition from $3.15 \mathrm{~min}$ to $5.0 \mathrm{~min}$. The total run time was $5.0 \mathrm{~min}$.

The HPLC system was interfaced with a triple stage quadrupole mass spectrometer Finnigan ${ }^{\mathrm{TM}} \mathrm{TSQ}^{\circledR}$ Quantum Discovery Max (ThermoFisher, San Jose, CA, USA). Positive electrospray ionization interface parameters were as follows: spray voltage $4.5 \mathrm{kV}$, sheath gas and auxiliary gas (N2) 35 and 10 arbitrary units, respectively, capillary heater temperature $250^{\circ} \mathrm{C}$. The MS run was performed in the multiple reaction monitoring $(\mathrm{MRM})$ scanning mode. The adduct $\left[\mathrm{M}+\mathrm{NH} 4^{+}\right]$transitions $\mathrm{m} / \mathrm{z} 821.42 \rightarrow$ $\mathrm{m} / \mathrm{z} 768.53$ (collision energy at $20 \mathrm{eV}$ and Tube lens value at $135 \mathrm{~V}$ ) and $\mathrm{m} / \mathrm{z} 809.55 \rightarrow \mathrm{m} / \mathrm{z} 756.52$ (collision energy at $27 \mathrm{eV}$ and Tube lens value at $129 \mathrm{~V}$ ) were monitored for tacrolimus and ascomycin, respectively. Data acquisition and analysis were performed using LCQuan software, version 2.5.6 (ThermoFisher, San Jose, CA, USA).

\subsection{Preparation of standards (Std) and quality control (QC) samples}

Two batches of stock solutions of tacrolimus were independently prepared in methanol at a concentration of $1000 \mathrm{ng} / \mathrm{mL}$ (one for QC and one for Std). A stock solution of ascomycin was prepared in acetonitrile at a concentration of $500 \mathrm{ng} / \mathrm{mL}$. These stock solutions were stored at $-80^{\circ} \mathrm{C}$. Working solutions of each calibration Std and each QC level were daily prepared by dilution of the tacrolimus stock solution in methanol. A working solution of ascomycin used as internal standard (IS) was daily prepared in acetonitrile at the concentration of $250 \mathrm{ng} / \mathrm{mL}$.

Aliquots of $250 \mu \mathrm{L}$ of drug-free human bile were spiked with corresponding working solutions to obtain 6 non zero calibrators levels at $0.5,1,1.5,5,10,20 \mathrm{ng} / \mathrm{mL}$ and QC samples at 0.5 (Lower limit of quantification), 1.5 (Low), 10 (Medium) and $20 \mathrm{ng} / \mathrm{mL}$ (High). The percentage of organic solvent in bile was lower than $8 \%$.

\subsection{Sample preparation}

An aliquot of $250 \mu \mathrm{L}$ of bile was transferred into a $4 \mathrm{~mL}$ glass tube. IS was added $(40 \mu \mathrm{L}$ of ascomycin $250 \mathrm{ng} / \mathrm{mL}$ ) and the sample was diluted with $800 \mu \mathrm{L}$ of water and vortexed $3 \mathrm{~s}$. Then, precipitation was performed by adding $300 \mu \mathrm{L}$ of a mixture of acetonitrile / zinc sulphate $0.05 \mathrm{M}$ in water $1: 1 \mathrm{v} / \mathrm{v}$ followed by a liquid/liquid extraction using $2 \mathrm{~mL}$ of ethyl acetate. Samples were gently mixed for 10 min and centrifuged at $3000 \mathrm{~g}$ for $10 \mathrm{~min}$ at $4^{\circ} \mathrm{C}$. The supernatant was evaporated to dryness under nitrogen flow at room temperature. The sample was reconstituted with $500 \mu \mathrm{L}$ of a mixture of water/acetonitrile $1: 1 \mathrm{v} / \mathrm{v}$, then $100 \mu \mathrm{L}$ of ammonium sulphate $40 \%$ in water were added and $12 \mu \mathrm{L}$ of the organic upper layer were injected in the LC-MS/MS system.

\subsection{Method development and validation}




\subsubsection{Method development}

In order to find the best procedure to extract tacrolimus from bile, several sample preparation conditions were investigated. Various mixtures of precipitant agents such as methanol, acetonitrile, zinc sulphate were tested. A pass through sample preparation plate was evaluated for phospholipids and proteins clean-up. Liquid-liquid extraction (LLE) was compared to solid phase extraction (SPE). Several solvents were compared for LLE among ethyl acetate, MTBE and dichloromethane. The optimal procedure was selected based on visual criteria, signal response and practical considerations.

\subsubsection{Method validation}

The analytical method was validated according to international guidelines from the European Medicines Agency on bioanalytical method validation [12].

\subsubsection{Selectivity, sensitivity}

Selectivity was investigated using six independent sources of human bile. Each one was used to prepare blank samples and samples spiked with tacrolimus at the expected lower limit of quantification (LLOQ). The lack of endogenous interferences was checked by thoroughly examining the chromatograms of blank samples in the retention window containing the peaks of the analyte or the IS. For each source of matrix, signal in blank should be less than $20 \%$ of the LLOQ area. The LLOQ was defined as the lowest amount of analyte in a sample determined with precision and accuracy within $\pm 20 \%$. Interferences coming from possible co-administered medications in liver transplants were evaluated for 46 drugs (see table 1). Because tacrolimus is extensively metabolized by the liver and transformed in oxidized and conjugated metabolites excreted in bile, potential interferences caused by co-eluted metabolites were investigated in samples from patient receiving tacrolimus.

\subsubsection{Linearity}

Method linearity was assessed by analyzing calibration samples spiked with the analyte at 6 concentration levels. Calibration standards analysis was performed over three different days. Calibration curves were established by plotting the peak area ratio of the target compounds to the IS versus the nominal concentrations. The homoscedasticity assumption for linear regression analysis was tested using the F-test. A minimum of $75 \%$ of the standard calibration samples had to be in the $\pm 15 \%$ range (LLOQ: $\pm 20 \%$ ) of the nominal value.

\subsubsection{Accuracy and precision}

Accuracy and precision were determined by replicate analysis of samples containing known amounts of tacrolimus daily prepared at each concentration level (LLOQ, Low, Medium, High). Within-day accuracy and precision were determined by analyzing QCs in five replicates in a single validation batch. Between-day accuracy and precision were determined by repeating analysis of five replicates over three different days. Precision was assessed by calculating the coefficient of variation (CV). Between-day precision data were compared using one-way ANOVA. Accuracy was reported as the relative error 
(RE) or bias to the theoretical value. The acceptance criteria for precision and accuracy were $\pm 15 \%$ except for LLOQ which should not deviate more than $20 \%$.

\subsubsection{Carry over}

Carry-over was evaluated by sequentially injecting an upper limit of quantification (ULOQ) sample (highest calibration standard) immediately followed by an extracted blank sample. The response in the blank matrix injection at the retention time region of tacrolimus should be less than $20 \%$ of the mean response at the LLOQ.

\subsubsection{Extraction recovery and matrix effect}

Recovery and matrix effect were assessed for each QC level with the post extraction addition technique adapted from Matuszewski et al. [14]. QC samples were prepared by spiking drug-free bile from 6 different sources and were extracted according to the procedure described above (samples A). For each source, blank bile samples were extracted and post-fortified with tacrolimus and IS at the same concentrations than in the QC extracts (samples B). Neat solutions (samples C) were prepared in duplicate with the extraction solution spiked with tacrolimus and ascomycin at the same concentrations as in the extracts A and B. Recoveries were calculated as follow: recovery $(\%)=$ (peak area of sample A / peak area of sample B) x100. Absolute matrix effects of each source were estimated for tacrolimus and the IS by matrix factors (MF) determined as $\mathrm{MF}=$ (peak area of sample B / peak area of sample C) x100. IS corrected MF was calculated by dividing the MF of the tacrolimus by the MF of the IS. The $\mathrm{CV}$ of the IS-normalized MF calculated from the 6 lots of matrix should not be greater than $15 \%$.

\subsubsection{Stability}

Stability of tacrolimus in bile was assessed for samples prepared in blank bile from three different sources and fortified at QCs level concentrations and stored during 20 hours at room temperature. Longterm stability covering a 6 months period of storage at $-80^{\circ} \mathrm{C}$ was also evaluated and after 3 freeze-thaw cycles at $-80^{\circ} \mathrm{C}$. Stability of the extract in the auto-sampler was assessed by re-injecting extracted calibration curve and QCs low, medium, high vials kept 24 hours at $15^{\circ} \mathrm{C}$. Stability of tacrolimus stock solution in methanol stored at $-80^{\circ} \mathrm{C}$ for 4 years was also studied. Stability was claimed if bias between tested condition and freshly prepared sample at the same concentration was no more than $\pm 15 \%$. Besides, it is assumed that Tacrolimus-glucuronide metabolites are excreted in bile, so it was worth checking whether the glucuronide form could be reversely transformed in the parent molecule (nonmetabolized tacrolimus) by the glucuronidase enzymes found in bile. Thus, bile samples from 6 patients treated with tacrolimus were collected for 2 hours on ice to inhibit any enzymatic activities. Aliquots were withdrawn and incubated for 15 hours at room temperature or at $37^{\circ} \mathrm{C}$ with a mixture of betaglucuronisases in $\mathrm{pH} 5.0$ acetate buffer $(5000 \mathrm{UI} / \mathrm{mL})$. The enzymes from three separate origins were used to ensure the best catalytic activity as possible. A control aliquot was immediately stored at $-80^{\circ} \mathrm{C}$ after collection. Comparison of tacrolimus concentrations between each experimental condition allowed highlighting any overestimation of the bile concentration of the immunosuppressant due to a back- 
conversion of a metabolite into the parent drug during the period of bile collection at the patient bedside.

\subsubsection{Clinical application}

The LC-MS/MS method was applied after validation to two clinical applications. Bile was collected in recent liver transplant recipients and following the onset of twice daily tacrolimus treatment. First, tacrolimus biliary concentrations were measured in sequential fractions ( 0 to $2 \mathrm{~h}, 2$ to $4 \mathrm{~h}, 4$ to $6 \mathrm{~h}$ and 6 to $10 \mathrm{~h}$ after tacrolimus intake) of fresh bile. A total of 13 sequential data sets coming from 6 individual patients were collected. The objective was to explore the excretion profile of tacrolimus in bile after drug intake. A second application aimed at studying the correlation between whole-blood tacrolimus trough concentrations and tacrolimus biliary concentrations or biliary excretion rates over a 12-hour collection period at the patient bedside. This analysis was intended to reflect liver exposition to tacrolimus over a drug intake period. Whole-blood trough concentration is the parameter used routinely to monitor immunosuppressive treatment. EDTA blood samples were collected simultaneously to bile samples just before tacrolimus administration in 30 liver transplant recipients. Tacrolimus concentrations were determined in blood using an in-house validated HPLC-MS/MS method adapted from the literature [15]. Linear regression and Pearson's correlation coefficient were used to investigate the correlation between blood and bile parameters.

The exact volumes of bile excreted during each collection period were carefully monitored to be able to express results in amount of tacrolimus excreted during a given period of time. This allowed comparing results between patients independently from the biliary flow rate.

The study was part of a clinical trial approved by the local ethical committee $\left(\mathrm{N}^{\circ} 16.45\right)$ and has been declared on clinicaltrials.gov (NCT02820259).

3.

\section{$\underline{\text { Results }}$}

\subsection{Method development}

The composition of bile is complex as it contains various elements such as water, electrolytes and a number of organic molecules such as bile acids, cholesterol, phospholipids and bilirubin. Consequently, a compromise had to be found between interfering compounds removal and analyte of interest recovery. In order to clean up the extract, to minimize matrix effect and to obtain an acceptable peak shape, the sample preparation procedure was optimized. A step of precipitation was necessary to remove solid particles from the extract. A mixture of acetonitrile, zinc sulphate and water displayed good precipitant properties and partially avoided extraction of yellow biliary pigments compared to precipitation with an organic solvent alone (acetonitrile or methanol). SPE extraction using HLB plate or proteins and phospholipids removal with Ostro® plate led to cleaner extracts but were associated with lower tacrolimus recovery. Because tacrolimus is a lipophilic drug, analyte recovery was improved with LLE using an organic solvent. Ethyl acetate was chosen because it provided the best peak shape and a high recovery. Regarding practical aspects, ethyl acetate was also preferred to MTBE and dichloromethane because its viscosity allowed more accurate pipetting. 


\subsection{Validation}

\subsubsection{Selectivity, sensitivity}

There were no interferences from either endogenous compounds or possible co-administered drugs at the retention times of tacrolimus and ascomycin (respectively 2.30 and $2.28 \mathrm{~min}$ ) in human bile samples. As a consequence of the high specificity of the tandem mass spectrometric detection, no baseline separation between analytes was necessary. Signal of noise peaks in blank samples were less than $20 \%$ of the areas of tacrolimus in spiked samples at the LLOQ concentration. However, when incurred patient samples were analyzed to look for metabolite interferences, a co-eluted peak appeared a few seconds before tacrolimus peak on the same MS/MS m/z transition than tacrolimus. Chromatographic resolution between these peaks was not good enough to quantify tacrolimus accurately. Consequently, liquid chromatography parameters had to be optimized using gradient elution (reported above) instead of isocratic elution (initially used during method development) to eliminate the interfering peak. It is assumed that this co-eluted peak comes from tacrolimus-glucuronide dissociation in the MS source. Since glucuronide metabolite is more hydrophilic than the parent drug, it is eluted before it in reverse phase mode. This hypothesis was confirmed using beta-glucuronidases mixture to force glucuronide hydrolysis before extraction. Six incurred patient bile samples were incubated before extraction 15 hours at room temperature without beta-glucuronidase (condition $\mathrm{A}$ ) or 15 hours at $37^{\circ} \mathrm{C}$ with a mixture of beta-glucuronidase in $\mathrm{pH} 5.0$ buffer (condition B). In condition B, the metabolite was back converted to tacrolimus before extraction and only one peak appeared on tacrolimus chromatogram at the correct retention time (using isocratic elution). As expected, tacrolimus peak area was significantly higher in condition $\mathrm{B}$ than in condition $\mathrm{A}$ (tacrolimus response ratio mean increase $\pm \mathrm{SD}=7.2 \pm 3.1$ ). A representative chromatogram is presented in Figure 1.

\subsubsection{Linearity}

The linearity of the method was obtained over the calibration range using linear regression. The best fit was obtained with a weighing factor of $1 / x$ to achieve homoscedasticity. Back calculated concentrations of the calibration standards were within the acceptance criteria $( \pm 15 \%$ of the target concentration, except $\pm 20 \%$ at the LLOQ) and the coefficient of correlation was $>0.99$ for every validation analysis. Slopes, intercepts and coefficient of determination mean values and standard-deviations were respectively as follow $(\mathrm{n}=3): 0.095 \pm 0.016,0.008 \pm 0.012,0.996 \pm 0.001$.

\subsubsection{Accuracy and precision}

Results of within-day and between-day precision and accuracy determined at four concentrations are detailed in table 2. They fulfilled the acceptance criteria since bias and CV did not exceed $20 \%$ for LLOQ and $15 \%$ for other QC concentrations.

\subsubsection{Carry over}


No carry-over was observed in the validation experiments as the responses of the blank sample after the injection of an ULOQ sample were less than $20 \%$ of the response of the LLOQ samples.

\subsubsection{Extraction recovery and matrix effect}

Recoveries were high and close to $95 \%$ for tacrolimus and ascomycin at low and high concentrations. Matrix effects determined from 6 different sources are presented in table 3. A significant absolute matrix effect due to ion enhancement was observed. There was also a relative matrix effect close to $20 \%$ within the concentration range. However, matrix effect was totally corrected by the IS (ascomycin) since mean corrected matrix factors were close to 1 and variation among samples from different sources were less than $15 \%$ at each concentration level, which is defined to be acceptable by the guidelines [12].

\subsubsection{Stability}

As shown in table 4, at room temperature, tacrolimus was stable in bile for 20 hours. This is relevant for clinical applications because stability should cover the time range from the collection at the patient bedside (about 12 hours) to the sample transport to the laboratory. No drug loss was observed after 6 months of storage at $-80^{\circ} \mathrm{C}$, neither after 3 freeze and thaw cycles. Extracts were found stable in an auto-sampler set at $15^{\circ} \mathrm{C}$ for 24 hours. There was no decrease in tacrolimus stock solution concentration stored 4 years at $-80^{\circ} \mathrm{C}$. Bile storage at room temperature for 15 hours (to mimic pre-analytic conditions) did not result in back transformation of tacrolimus-glucuronide metabolite in tacrolimus meaning that no hydrolysis occurred during bile collection at patient bedside. Tacrolimus concentration should not be overestimated because of beta-glucuronisase enzymes present in bile. Nevertheless, sample incubation with a cocktail of beta-glucuronidases in optimal catalytic conditions confirmed the relevance of this concern because tacrolimus-glucuronide was able to be directly back-transformed in tacrolimus after hydrolysis increasing in a very large extend tacrolimus signal compared to a control sample.

\subsubsection{Clinical application}

The method was successfully applied to the analysis of bile in patient samples. Representative ion chromatograms of tacrolimus of a blank sample (A), a sample spiked at the LLOQ (B) and a patient sample (C) are shown in figure 2. Measurement of tacrolimus concentrations in bile in sequential fractions allowed calculating tacrolimus amounts and tacrolimus excretion rates for the corresponding collection period. Tacrolimus mean excretion rate was (mean \pm SD) $25.4 \pm 17.4 \mathrm{ng} / \mathrm{h}$ during the first 2 hours following drug intake and decreased slowly over the day to $14.0 \pm 7.7 \mathrm{ng} / \mathrm{h} 10$ hours after drug administration. Results are reported in table 5. Mean tacrolimus excretion profile in bile is represented in figure $3 \mathrm{~A}$ as a mean excretion rate over time, and in figure $\mathrm{B}$ as mean cumulative amount over time. The second clinical application aimed at evaluating correlation between whole-blood tacrolimus concentrations and tacrolimus bile concentrations or tacrolimus bile amounts. Mean tacrolimus concentration in bile collected in 30 liver transplant recipients was $1.1 \pm 0.6 \mathrm{ng} / \mathrm{mL}$. This value was reported to the volume of bile produced over 12 hours and the mean amount of tacrolimus found in the bile collection was $192 \pm 122 \mathrm{ng}$. Mean biliary tacrolimus excretion rate on 12 hours was $16.0 \pm 10.2 \mathrm{ng} / \mathrm{h}$. 
No correlation was found between the amount of tacrolimus excreted in bile over the 12-hour period between two drug intakes and tacrolimus trough concentration in whole blood $(p=0.88)$. Moreover, no correlation was found between the concentration of tacrolimus measured in bile collected over the 12hour period between two drug intakes and tacrolimus trough concentration in whole blood $(p=0.16)$ (figure 4A and 4B).

\section{Discussion}

To the best of our knowledge, this is the first extensive report of a LC-MS/MS method aiming at quantitating tacrolimus in bile. Two teams also developed an analytical method to measure tacrolimus in bile using chromatographic separation $[9,10]$. These studies were conducted some decades ago with ancient instruments less sensitive and less specific than now days. For instance, Firdaous et al. used a HPLC method coupled with an immune-enzymatic detection which is not the actual gold-standard for immunosuppressive drugs quantitation [9]. Indeed, immunological techniques can lead to crossreactivity between tacrolimus and its metabolites which may cause a unacceptable positive bias in the measurement [16]. Shimomura et al. measured tacrolimus and three of its main metabolites in bile using an LC-MS/MS system [8]. However, nothing was reported about the analytical method performances.

In liver transplant patients, the relationship between tacrolimus efficacy and intracellular or tissue (hepatic biopsy) concentrations of the drug has been reported to be closer than with whole-blood concentrations [5]. This is not surprising because the intracellular fraction of the drug is the fraction available at the site of action and tissue fraction represents the local concentration of the drug in the targeted graft. Both of these fractions could also be better related to tacrolimus free fraction (i.e. the active fraction of the drug). Thus, monitoring intracellular or tissue tacrolimus concentrations appears to be of better relevance than monitoring whole-blood concentrations. Unfortunately, measuring intracellular concentrations is time-consuming, expensive and requires expertise which is only available in few centers. In the same way, measuring tissue concentrations requires time and money and can only be conducted on hepatic biopsy which is an invasive procedure. Facing these difficulties, we have developed a method to measure tacrolimus in bile. Indeed, tacrolimus concentrations in bile could reflect at the same time the local concentration of the drug, as bile is a direct product of hepatocytes efflux, and the free-fraction of the drug, as tacrolimus is freely eliminated through biliary secretion. During the early post-operative period, bile produced by the liver graft could be easily collected when a biliary drainage is left in the biliary tract. It is intended to prevent early biliary leakage and stricture by reducing intra-ductal pressure [17] as well as to confirm bile production which is considered as a good marker of graft function. It then allows to easily access to the bile and tacrolimus concentration can be measured in it.

Measuring drugs concentrations in bile appears to be challenging. Bile is a complex matrix containing bile acids, phospholipids and bilirubin. Ensuring appropriate selectivity of the method can be a complex process and involves: obtaining sufficient extraction process, assessing drug stability in the matrix, ensuring adequate chromatographic separation, avoiding matrix effect and ensuring lack of influence of potential in-source dissociation of glucuronide into the parent drug. 
More than $95 \%$ of tacrolimus is excreted in bile almost exclusively as metabolites [18]. As a result, limited quantity of unchanged drug is eliminated in bile and the sensitivity of the method is crucial. The sample preparation of the present method with its high extraction process allowed reaching a lower limit of quantification of $0.5 \mathrm{ng} / \mathrm{mL}$. This limit has been shown to be sufficient when the method was applied to clinical samples. Even if the drug is mainly metabolized through phase I mechanisms leading to demethylated and hydroxylated metabolites [7,19,20], part of tacrolimus is directly conjugated via UDP-glucuronyltransferase (UGT) 1A4 [21]. This tacrolimus-glucuronide might be hydrolyzed in bile during collection and/or storage. This phenomenon was explored as it could result in overestimation of drug concentration. Particularly, there was no difference between tacrolimus measured in bile patients collected on ice (in order to inhibit glucuronidase activity) and assayed immediately or after 15 hours at room temperature. Then, we demonstrated that no back-conversion of the glucuronide metabolite occurred during the pre-analytical steps. Degradation of the unchanged drug within the matrix was also investigated. In the present work, we ensured drug stability during collection for 12 hours as well as short-term and long term stability under various conditions of temperature. As presented earlier in this manuscript, in-source dissociation of tacrolimus-glucuronide was a cause of concern during method development. Such a phenomenon has already been described for other directly conjugated drugs $[22,23]$. In the first steps of the method development, a duplication in patients' tacrolimus chromatographic peaks appeared. We put forth the hypothesis that this duplication was due to tacrolimus-glucuronide dissociated within the ionization source with the metabolite being eluted earlier than the parent compound. Adding a glucuronidase enzymes cocktail to the bile of transplant recipients collected on ice resulted in an increase in tacrolimus concentrations and in the disappearance of the peak with the shorter retention time. This confirmed that a part of tacrolimus is directly conjugated via UGT, as demonstrated by Laverdière et al., and that in-source dissociation of tacrolimus-glucuronide into unchanged tacrolimus has to be clearly assessed to avoid the risk of overestimation of biliary tacrolimus concentration. Modifying chromatographic gradient allowed us separating tacrolimus from its metabolites. It highlighted the relevance of the analysis of incurred patient samples in the early steps of the validation procedure and how selectivity issue might be a critical point when analyzing such a complex matrix.

The present fully validated LC-MS/MS method was applied to two clinical applications. First, we measured biliary tacrolimus concentrations in sequential fractions ( 0 to $2 \mathrm{~h}, 2$ to $4 \mathrm{~h}, 4$ to $6 \mathrm{~h}$ and 6 to $10 \mathrm{~h}$ post drug intake) of fresh bile collected in recently liver transplant recipients. Despite high interindividual variability, this clinical application provided interesting information. Tacrolimus appeared to be excreted to a greater extent during the first two hours post-dose administration. Tacrolimus elimination can thereby be studied using this novel LC-MS/MS method.

Finally, we have determined tacrolimus concentrations in bile collected during 12 hours and investigated the relationship between, tacrolimus amount excreted in bile or tacrolimus concentration in bile, and tacrolimus concentration in whole-blood in 30 liver transplant recipients. No correlation was found between tacrolimus excreted through 12-hours bile secretion and the trough whole-blood concentration of the drug. As tacrolimus concentration in bile could better reflect local and unbound concentration of the drug, and because it does not appear to be correlated with whole-blood 
concentration, this concentration might be more closely related to the immunosuppressive effect of the drug. This hypothesis have to be confirmed by showing a significant correlation between tacrolimus concentration in bile and tacrolimus concentration within PBMC which is recognized as a good marker of the drug immunosuppressive activity. Our team is currently performing this study (STABILE study, clinical trial: NCT02820259). The measurement of tacrolimus concentration in bile should therefore be further evaluated as a potential way of monitoring the drug effect. The present method should then be applied to evaluate the value of such a biomarker in monitoring treatments in liver transplant recipients. Of course, there are limitations in the usefulness of this LC-MS/MS method. First, this method is only effective when a biliary drainage is present, which is not a consensual approach. However, in our center, we think that this method is relevant especially when considering the use of graft from extended criteria donor and is therefore systematically performed. Then, as T-tube drain is usually clamped between 7 to 10 post-operative days, monitoring of tacrolimus in bile is only possible thorough the early postoperative period. However, the first week after transplantation is the most critical and difficult period in management of transplanted patients. Indeed, the progressive liver function recovery has a major impact on the pharmacokinetics of immunosuppressive drugs which is not taken in consideration by blood dosage of tacrolimus, resulting in difficulty in dose adjustment during this period. Therefore, occurrence of ACR and adverse effects related to tacrolimus could be more prevalent during the first post-operative days requiring maybe a therapeutic drug monitoring of better performance than blood dosage of tacrolimus can offer.

\section{Conclusion}

An HPLC-MS/MS method has been thoroughly validated for the quantification of tacrolimus in bile. An extraction process based on protein precipitation and liquid-liquid extraction leads to high recovery and good analytical performances since the assay fulfilled acceptance criteria of international guidelines. The method was successfully applied to the quantification of tacrolimus in bile from liver transplant recipients. It allowed getting preliminary data about tacrolimus excretion profile in bile and the lack of correlation between tacrolimus whole blood concentration and tacrolimus liver exposition. Thus, this alternative and innovative analytical approach of tacrolimus bio-analysis appears suitable for further studies evaluating biliary tacrolimus concentration as a new pharmacological marker of immunosuppressive activity.

\section{Conflict of interest statement}

Florian Lemaitre received a research grant from Astellas Pharma and has received speaker fees from Chiesi SA

Funding: The study was partially funded by the COmite de la REcherche Clinique Translationnelle (CORECT) of the Rennes University Hospital.

\section{Acknowledgements}


The study was partially funded by the COmité de la REcherche Clinique Translationnelle (CORECT) of the Rennes university hospital.

\section{REFERENCES}

[1] P. Wallemacq, V.W. Armstrong, M. Brunet, V. Haufroid, D.W. Holt, A. Johnston, D. Kuypers, Y. Le Meur, P. Marquet, M. Oellerich, others, Opportunities to optimize tacrolimus therapy in solid organ transplantation: report of the European consensus conference, Ther. Drug Monit. 31 (2009) 139-152.

[2] A.W. Thomson, C.A. Bonham, A. Zeevi, Mode of action of tacrolimus (FK506): molecular and cellular mechanisms, Ther. Drug Monit. 17 (1995) 584-591.

[3] R. Venkataramanan, A. Swaminathan, T. Prasad, A. Jain, S. Zuckerman, V. Warty, J. McMichael, J. Lever, G. Burckart, T. Starzl, Clinical pharmacokinetics of tacrolimus, Clin. Pharmacokinet. 29 (1995) 404-430. doi:10.2165/00003088-199529060-00003.

[4] D.J. Touw, C. Neef, A.H. Thomson, A.A. Vinks, Cost-Effectiveness of Therapeutic Drug Monitoring Committee of the International Association for Therapeutic Drug Monitoring and Clinical Toxicology, Costeffectiveness of therapeutic drug monitoring: a systematic review, Ther. Drug Monit. 27 (2005) 10-17.

[5] A. Capron, J. Lerut, D. Latinne, J. Rahier, V. Haufroid, P. Wallemacq, Correlation of tacrolimus levels in peripheral blood mononuclear cells with histological staging of rejection after liver transplantation: preliminary results of a prospective study: PBMCs tacrolimus levels and graft rejection, Transpl. Int. 25 (2012) 41-47. doi:10.1111/j.1432-2277.2011.01365.x.

[6] C.E. Staatz, S.E. Tett, Clinical pharmacokinetics and pharmacodynamics of tacrolimus in solid organ transplantation, Clin. Pharmacokinet. 43 (2004) 623-653.

[7] K. Iwasaki, Metabolism of tacrolimus (FK506) and recent topics in clinical pharmacokinetics, Drug Metab. Pharmacokinet. 22 (2007) 328-335.

[8] M. Shimomura, S. Masuda, M. Goto, T. Katsura, T. Kiuchi, Y. Ogura, F. Oike, Y. Takada, S. Uemoto, K. Inui, Required transient dose escalation of tacrolimus in living-donor liver transplant recipients with high concentrations of a minor metabolite M-II in bile, Drug Metab. Pharmacokinet. 23 (2008) 313-317.

[9] I. Firdaous, R.K. Vèrbeeck, A. Hassoun, J.M. Langrehr, P.E. Wallemacq, Excretion of tacrolimus glucuronides in human bile, Eur. J. Drug Metab. Pharmacokinet. 22 (1997) 217-221.

[10] U. Christians, F. Braun, N. Kosian, M. Schmidt, H.M. Schiebel, L. Ernst, C. Kruse, M. Winkler, I. Holze, A. Linck, High performance liquid chromatography/mass spectrometry of FK 506 and its metabolites in 
blood, bile, and urine of liver grafted patients, Transplant. Proc. 23 (1991) 2741-2744.

[11] N.R. Srinivas, R. Mullangi, An overview of various validated HPLC and LC-MS/MS methods for quantitation of drugs in bile: challenges and considerations, Biomed. Chromatogr. 25 (2011) 65-81. doi:10.1002/bmc.1532.

[12] Guideline on bioanalytical method validation. European medicines agency (2011) http://www.ema.europa.eu/docs/en_GB/document_library/Scientific_guideline/2011/08/WC500109686.pdf (accessed July 25, 2016).

[13] I.R. Dubbelboer, A. Pohanka, R. Said, S. Rosenborg, O. Beck, Quantification of tacrolimus and three demethylated metabolites in human whole blood using LC-ESI-MS/MS, Ther. Drug Monit. 34 (2012) 134-142. doi:10.1097/FTD.0b013e31824b0bfb.

[14] B.K. Matuszewski, M.L. Constanzer, C.M. Chavez-Eng, Strategies for the assessment of matrix effect in quantitative bioanalytical methods based on HPLC-MS/MS, Anal. Chem. 75 (2003) 3019-3030.

[15] C. Seger, K. Tentschert, W. Stöggl, A. Griesmacher, S.L. Ramsay, A rapid HPLC-MS/MS method for the simultaneous quantification of cyclosporine A, tacrolimus, sirolimus and everolimus in human blood samples, Nat. Protoc. 4 (2009) 526-534. doi:10.1038/nprot.2009.25.

[16] C. Seger, M. Shipkova, U. Christians, E.M. Billaud, P. Wang, D.W. Holt, M. Brunet, P.K. Kunicki, T. Pawinski, L.J. Langman, others, Assuring the Proper Analytical Performance of Measurement Procedures for Immunosuppressive Drug Concentrations in Clinical Practice: Recommendations of the International Association of Therapeutic Drug Monitoring and Clinical Toxicology Immunosuppressive Drug Scientific Committee, Ther. Drug Monit. 38 (2016) 170-189.

[17] M. Wojcicki, P. Milkiewicz, M. Silva, Biliary Tract Complications after Liver Transplantation: A Review, Dig. Surg. 25 (2008) 245-257. doi:10.1159/000144653.

[18] A. Möller, K. Iwasaki, A. Kawamura, Y. Teramura, T. Shiraga, T. Hata, A. Schäfer, N.A. Undre, The disposition of 14C-labeled tacrolimus after intravenous and oral administration in healthy human subjects, Drug Metab. Dispos. Biol. Fate Chem. 27 (1999) 633-636.

[19] M. Sattler, F.P. Guengerich, C.H. Yun, U. Christians, K.F. Sewing, Cytochrome P-450 3A enzymes are responsible for biotransformation of FK506 and rapamycin in man and rat, Drug Metab. Dispos. Biol. Fate Chem. 20 (1992) 753-761.

[20] P.E. Wallemacq, R. Reding, FK506 (tacrolimus), a novel immunosuppressant in organ transplantation: clinical, biomedical, and analytical aspects., Clin. Chem. 39 (1993) 2219-2228.

[21] I. Laverdiere, P. Caron, M. Harvey, E. Levesque, C. Guillemette, In Vitro Investigation of Human UDP-Glucuronosyltransferase Isoforms Responsible for Tacrolimus Glucuronidation: Predominant Contribution of UGT1A4, Drug Metab. Dispos. 39 (2011) 1127-1130. doi:10.1124/dmd.111.039040. 
[22] J.-N. Mess, E.-R. Bérubé, M. Furtado, F. Garofolo, A practical approach to reduce interference due to in-source collision-induced dissociation of acylglucuronides in LC-MS/MS, Bioanalysis. 3 (2011) 1741-1751. doi:10.4155/bio.11.156.

[23] M. Vogeser, R. Zachoval, U. Spöhrer, K. Jacob, Potential lack of specificity using electrospray tandemmass spectrometry for the analysis of mycophenolic acid in serum, Ther. Drug Monit. 23 (2001) 722-724. 
Figure 1: Representative LC-MS/MS chromatograms of tacrolimus (for tacrolimus m/z MS/MS transition) analysed in an incurred patient bile sample. An un-resolved peak, coming from a metabolite back conversion to tacrolimus in the MS system source, was eluted with tacrolimus in sample incubated $15 \mathrm{~h}$ at room temperature (Figure A). After hydrolysis before extraction $\left(15 \mathrm{~h}\right.$ at $\left.37^{\circ} \mathrm{C}, \mathrm{pH} 5\right)$ with a cocktail of beta-glucuronidases, the metabolite was extensively converted to tacrolimus and only a single peak of higher area was detected by the MS system (Figure B). Signals absolute intensities are reported as area under the curve next to corresponding peaks.

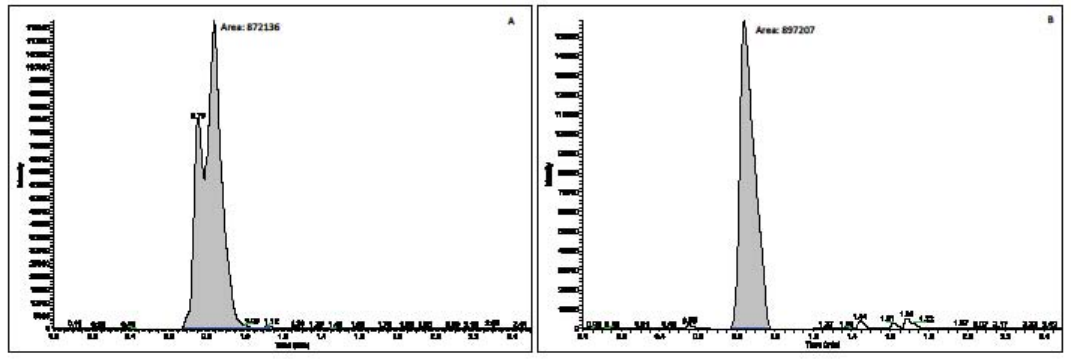

Figure 2: Representative LC-MS/MS chromatograms of tacrolimus analysed in a blank sample (A), a sample spiked at the LLOQ (B) and a patient sample (C). The first peak in the patient sample (retention time $1.5 \mathrm{~min}$ ) comes from the glucuronide dissociation in the LCMS system. 


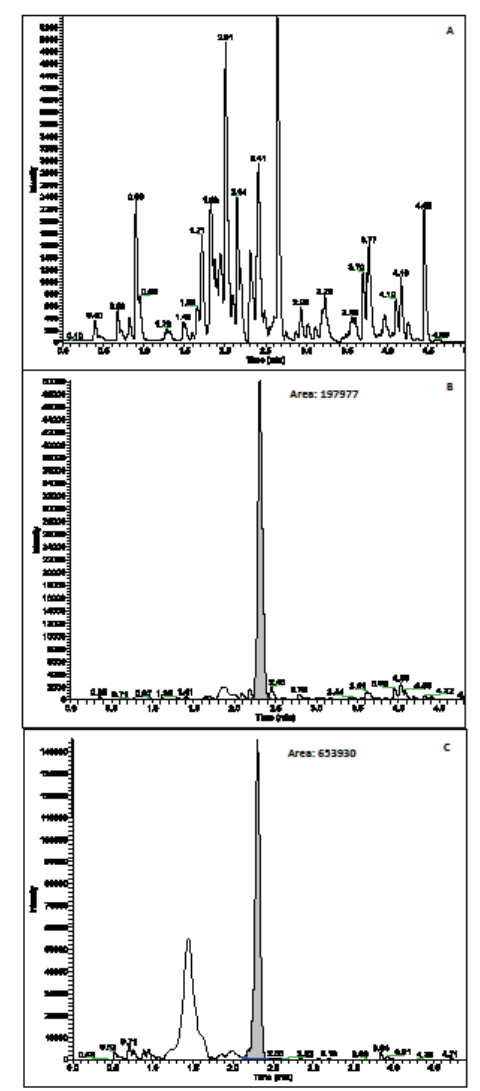


Figure 3: Excretion profile of tacrolimus in bile. Excretion rate according to the collection period post tacrolimus administration (mean $\pm \mathrm{SD}, \mathrm{n}=13$, Figure $\mathrm{A}$ ). Cumulated amount of tacrolimus excreted in bile along the sequential collection (black histograms) and total excretion during the previous $12 \mathrm{~h}$ (grey histogram) $($ mean \pm SD, $n=13$, Figure B).

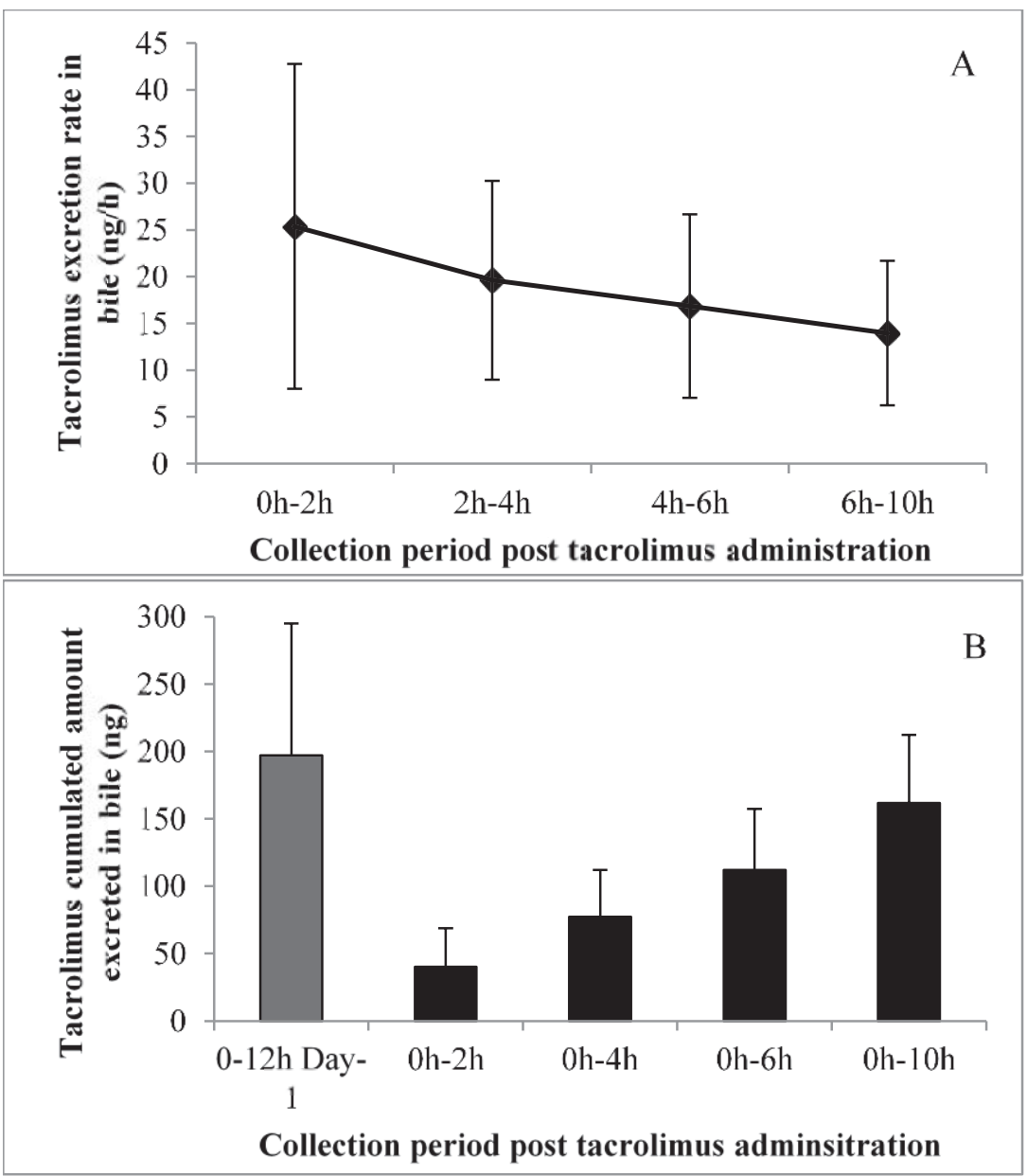

Figure 4: Correlation plots between tacrolimus trough concentrations in whole blood and tacrolimus amount (Figure $\mathrm{A}, \mathrm{p}=0.88$ ) or tacrolimus concentration (Figure $\mathrm{B}, \mathrm{p}=0.16$ ) measured in bile of liver transplant patients (12-hour collection). Trend curves and their respective equations and coefficients of determination are reported 
$(n=30)$.
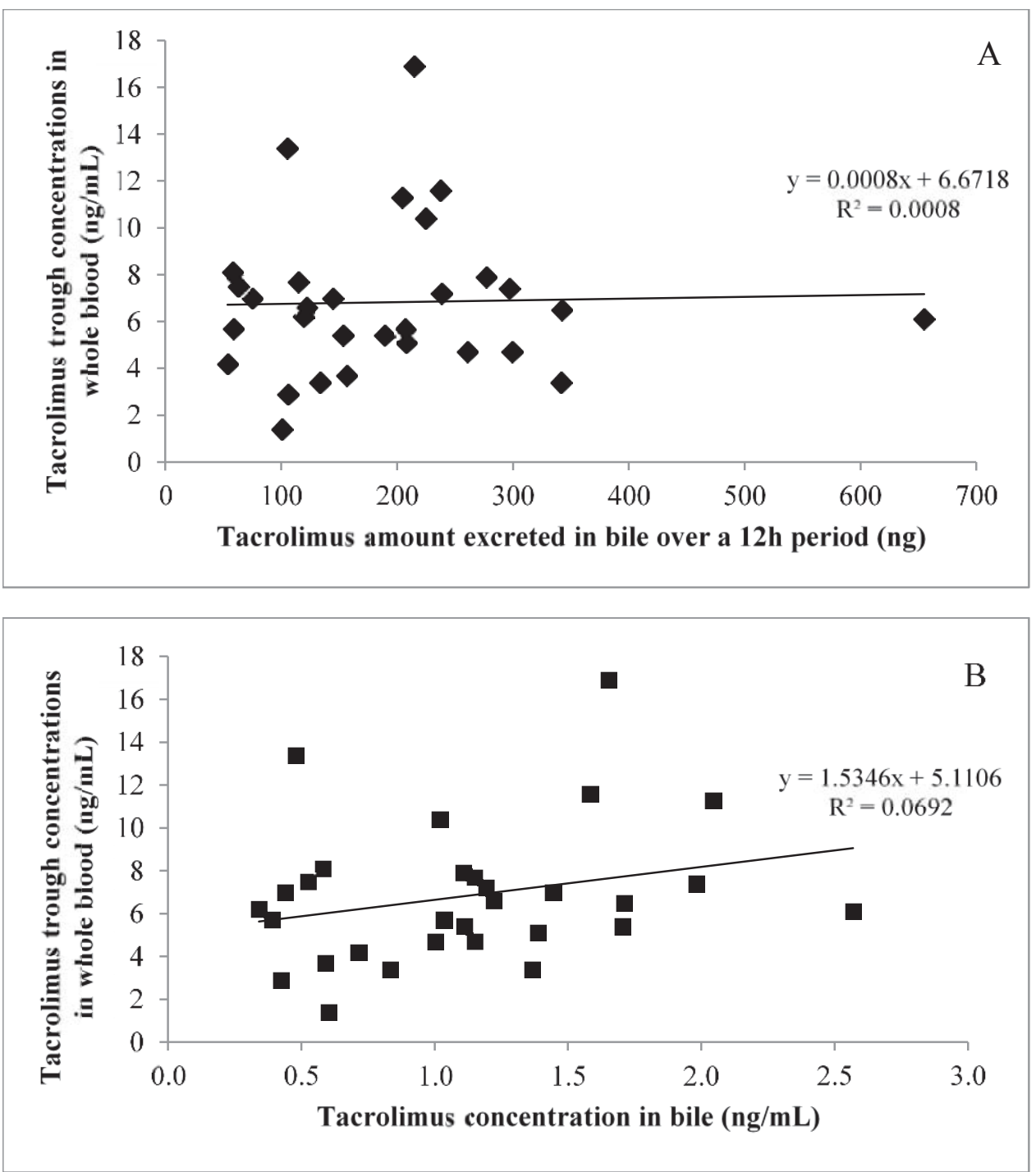
Table 1 : Drugs evaluated for interferences with tacrolimus and ascomycin in bile samples

\begin{tabular}{|l|l|l|l|l|}
\hline \multicolumn{2}{|l|}{ Antibacterial drugs } & Antiviral drugs & $\begin{array}{l}\text { Immunosupressive } \\
\text { drugs }\end{array}$ & $\begin{array}{l}\text { Antifungal } \\
\text { drugs }\end{array}$ \\
\hline Amoxicillin & Ciprofloxacin & Aciclovir & Prednisone & Voriconazole \\
\hline Cefazolin & Rifampicin & Ganciclovir & Prednisolone & Posaconazole \\
\hline Céfépime & Clindamicin & Ribavirin & Methylprednisolone & Itraconazole \\
\hline Cefotaxime & Isoniazid & Tenofovir & Sirolimus & \\
\hline Ceftazidime & Ethambutol & Atazanavir & Everolimus & \\
\hline Ceftriaxone & Pyrazinamide & Darunavir & Mycophenolate & \\
\hline Cefuroxime & Gentamicin & Efavirenz & & \\
\hline Cloxacillin & Amikacin & Etravirine & & \\
\hline Oxacillin & Vancomycin & Lopinavir & & \\
\hline Piperacillin & & Maraviroc & & \\
\hline Sulfamethoxazole & & Nevirapine & & \\
\hline Trimethoprim & & Raltegravir & & \\
\hline Ertapenem & & Ritonavir & & \\
\hline Imipenem & & & & \\
\hline Meropenem & & & & \\
\hline
\end{tabular}


Table 2 : Within-day and between-day accuracy and precision of tacrolimus analysis in bile

\begin{tabular}{|l|l|l|l|}
\hline $\begin{array}{l}\text { Concentration } \\
\text { level }(\mathrm{ng} / \mathrm{ml})\end{array}$ & $\begin{array}{l}\text { Within day } \\
\text { precision } \\
(\mathrm{CV} \%, \mathrm{n}=5)\end{array}$ & $\begin{array}{l}\text { Between day } \\
\text { precision } \\
(\mathrm{CV} \%, \mathrm{n}=15)\end{array}$ & $\begin{array}{l}\text { Overall bias } \\
(\%, \mathrm{n}=15)\end{array}$ \\
\hline LLOQ $(0.5)$ & 8.1 & 11.5 & -0.55 \\
\hline QC low (1.5) & 6.0 & 10.7 & 0.08 \\
\hline QC medium (10) & 6.5 & 10.4 & 1.77 \\
\hline QC high $(20)$ & 4.7 & 7.7 & 1.49 \\
\hline
\end{tabular}


Table 3 : Matrix factors and relative matrix effects determined from 6 human bile sources

\begin{tabular}{|c|c|c|c|c|c|c|c|c|c|c|c|}
\hline \multicolumn{6}{|c|}{ Matrix effect } & \multicolumn{6}{|c|}{ IS corrected matrix effect } \\
\hline \multicolumn{2}{|c|}{ QC low } & \multicolumn{2}{|c|}{ QC medium } & \multicolumn{2}{|c|}{ QC high } & \multicolumn{2}{|c|}{ QC low } & \multicolumn{2}{|c|}{ QC medium } & \multicolumn{2}{|c|}{ QC high } \\
\hline $\begin{array}{l}\text { Mean } \\
\text { matrix } \\
\text { factor }\end{array}$ & $\begin{array}{l}\text { CV } \\
(\%)\end{array}$ & $\begin{array}{l}\text { Mean } \\
\text { matrix } \\
\text { factor }\end{array}$ & $\begin{array}{l}\text { CV } \\
(\%)\end{array}$ & $\begin{array}{l}\text { Mean } \\
\text { matrix } \\
\text { factor }\end{array}$ & $\begin{array}{l}\text { CV } \\
(\%)\end{array}$ & $\begin{array}{l}\text { Mean } \\
\text { matrix } \\
\text { factor }\end{array}$ & $\begin{array}{l}\text { CV } \\
(\%)\end{array}$ & $\begin{array}{l}\text { Mean } \\
\text { matrix } \\
\text { factor }\end{array}$ & $\begin{array}{l}\text { CV } \\
(\%)\end{array}$ & $\begin{array}{l}\text { Mean } \\
\text { matrix } \\
\text { factor }\end{array}$ & $\begin{array}{l}\text { CV } \\
(\%)\end{array}$ \\
\hline 1.58 & 22.4 & 1.37 & 24.4 & 1.44 & 19.2 & 1.11 & 11.4 & 1.09 & 10.5 & 1.03 & 6.1 \\
\hline
\end{tabular}


Table 4: Stability of tacrolimus in human bile

\begin{tabular}{|c|c|c|c|}
\hline $\begin{array}{l}\text { Concentration } \\
\text { levels }\end{array}$ & $\begin{array}{l}20 \mathrm{~h} \text { at Room } \\
\text { Temperature } \\
\left(\text { Overall bias }{ }^{1} \%\right) \\
(\mathrm{n}=9)\end{array}$ & $\begin{array}{l}6 \text { months }-80^{\circ} \mathrm{C} \\
\left(\operatorname{bias}^{1} \%\right) \\
(\mathrm{n}=3)\end{array}$ & $\begin{array}{l}3 \text { Freeze and Thaw cycle } \\
\text { at }-80^{\circ} \mathrm{C} \\
\left(\text { bias }^{1} \%\right) \\
(\mathrm{n}=3)\end{array}$ \\
\hline QC1 & -7.3 & \begin{tabular}{|l|}
10.3 \\
\end{tabular} & 3.7 \\
\hline QC2 & 4.5 & 2.5 & -6.5 \\
\hline QC3 & 2.4 & \begin{tabular}{|l|}
-1.3 \\
\end{tabular} & \begin{tabular}{|l|}
-7.9 \\
\end{tabular} \\
\hline QC4 & 2.3 & -3.2 & -8.8 \\
\hline \multicolumn{2}{|c|}{$\begin{array}{l}\text { Incurred patient bile sample incubated } \\
15 \mathrm{~h} \text { at Room Temperature } \\
\left(\text { bias }^{2} \%\right)(\mathrm{n}=6)\end{array}$} & \multicolumn{2}{|c|}{$\begin{array}{l}\text { Incurred patient bile sample incubated under } \\
\text { forced hydrolysis } 15 \mathrm{~h} \text { at } 37^{\circ} \mathrm{C} \text { with beta- } \\
\text { glucuronidase cocktail } \\
\left(\text { bias }^{2} \%\right)(\mathrm{n}=6)\end{array}$} \\
\hline-10.9 & & \begin{tabular}{|l|}
519.9 \\
\end{tabular} & \\
\hline \multicolumn{4}{|c|}{$\begin{array}{l}{ }^{1} \text { Bias compared to QCs freshly prepared } \\
{ }^{2} \text { Bias compared to control sample collected on ice to inactivate enzymatic activity and } \\
\text { immediately stored at }-80^{\circ} \mathrm{C}\end{array}$} \\
\hline
\end{tabular}


Table 5 : Quantitative parameters measured in sequential fractions of fresh bile

\begin{tabular}{|l|l|l|l|l|}
\hline $\begin{array}{l}\text { Collection } \\
\text { period post } \\
\text { drug intake }\end{array}$ & $\begin{array}{l}\text { Bile volume } \\
(\mathrm{mL})\end{array}$ & $\begin{array}{l}\text { Tacrolimus } \\
\text { concentration in } \\
\text { bile } \\
(\mathrm{ng} / \mathrm{mL})\end{array}$ & $\begin{array}{l}\text { Tacrolimus } \\
\text { amount } \\
(\mathrm{ng})\end{array}$ & $\begin{array}{l}\text { Tacrolimus } \\
\text { excretion rate } \\
(\mathrm{ng} / \mathrm{h})\end{array}$ \\
\hline $0 \mathrm{~h}-2 \mathrm{~h}$ & $39.9 \pm 19.2$ & $1.3 \pm 0.5$ & $50.8 \pm 34.7$ & $25.4 \pm 17.4$ \\
\hline $2 \mathrm{~h}-4 \mathrm{~h}$ & $31.6 \pm 9.2$ & $1.2 \pm 0.5$ & $36.0 \pm 23.7$ & $19.6 \pm 10.6$ \\
\hline 4h-6h & $30.0 \pm 13.3$ & $1.1 \pm 0.4$ & $33.7 \pm 19.6$ & $16.9 \pm 9.8$ \\
\hline 6h-10h & $57.7 \pm 23.4$ & $1.0 \pm 0.4$ & $55.9 \pm 31.0$ & $14.0 \pm 7.7$ \\
\hline Results are expressed as mean value $\pm \mathrm{SD}(\mathrm{n}=13)$ & & \\
\hline SD : Standard deviation & & & \\
\hline
\end{tabular}

